\title{
One-step codoping of reduced graphene oxide using boric and nitric acid mixture and its use in metal-free electrocatalyst
}

\author{
Huynh Ngoc Tien ${ }^{a}$, Coskun Kocabas ${ }^{b}$, Seung Hyun Hur ${ }^{a, *}$ \\ a School of chemical Engineering, University of Ulsan, Daehak-ro 93, Ulsan 680-749, South Korea \\ ${ }^{\mathrm{b}}$ Department of Physics, Bilkent University, 06800 Ankara, Turkey
}

\section{A R T I C L E I N F O}

\section{Article history:}

Received 4 October 2014

Accepted 23 December 2014

Available online 2 January 2015

Keywords:

Boron

Nitrogen

Doping

Oxygen reduction reaction

CO tolerance

\begin{abstract}
A B S T R A C T
In this study, the preparation of a highly efficient metal-free electrocatalyst, boron and nitrogen codoped reduced graphene oxide (BN-rGO), with an excellent durability is reported. The BN-rGO were prepared in one step using boric and nitric acid mixture, exhibiting highly improved oxygen reduction reaction (ORR) activity than those of the pristine GO and single doped rGOs. The electrocatalyst also showed the excellent long-term durability and CO tolerance than those of the commercial Pt/C catalysts.
\end{abstract}

(c) 2014 Elsevier B.V. All rights reserved.

\section{Introduction}

In recent years, cost-effective nonprecious metal and metalfree catalysts have been widely studied for alkaline anion exchange membrane fuel cells (AAEMFCs) [1,2]. The AAEMFCs offer several advantages over the proton exchange membrane fuel cells such as faster kinetic at electrodes for the oxygen reduction reaction and fuel oxidation in the alkaline environment and a lower cost by using metal free or nonprecious metal catalysts [3,4].

Reduced graphene oxide (rGO) exhibits both advanced chemical and physical adsorption capability owing to the abundant functional groups and high electrical conductivity of its welldeveloped $\mathrm{sp}^{2}$ networks, enabling it as an alternative to the $\mathrm{Pt} / \mathrm{C}$ catalysts in the fuel cell applications $[5,6]$. However, the zero band gap of graphene weakens its catalytic activity and limits its applications when it is used without metal components. The chemical doping of graphene or GO with heteroatoms is considered as an effective strategy to enhance the catalytic activity by tailoring its electronic environment [1,7-9].

In this study, we report the B and $\mathrm{N}$ codoped rGOs (BN-rGOs) synthesized by a simple one-step codoping process using mixed organic acids [10]. The lower and higher electronegativities of boron and nitrogen than that of carbon is believed to effectively modify the electronic structure of carbon to be more reactive toward oxygen. The BN-rGO fabricated using the mixture of boric and nitric acid exhibited excellent electrochemical performances

\footnotetext{
* Corresponding author.

E-mail address: shhur@ulsan.ac.kr (S.H. Hur).
}

such as high ORR activity and CO tolerance when used as a metalfree catalyst in the alkaline media.

\section{Experimental}

GO was prepared according to the Hummers method as described in our previous report [10]. To prepare B-rGO, the $\mathrm{N}-\mathrm{rGO}$, and $\mathrm{BN}-\mathrm{rGO}, \mathrm{GO}$ were mixed with $0.1 \mathrm{M}$ boric acid, nitric acid, and a mixture of boric and nitric acid in N-Methyl-2pyrrolidone (NMP) and maintained at $180{ }^{\circ} \mathrm{C}$ for $1 \mathrm{~h}$. Then, all the samples were annealed at $800{ }^{\circ} \mathrm{C}$ in argon atmosphere for $1 \mathrm{~h}$ after washing and drying. rGO was obtained by the thermal reduction of GO at same condition.

The catalyst suspensions in isopropanol $\left(10 \mathrm{mg} \mathrm{mL}^{-1}\right)$ were prepared by introducing a predetermined amount of sample powder in the pure solvent under sonication followed by dropping $10 \mu \mathrm{L}$ of Nafion solution ( $0.5 \mathrm{wt} \%$ in isopropanol) as the binder.

\section{Results and discussion}

The XPS survey spectra of the BN-rGO shown in Fig. 1(a) confirm the incorporation of $\mathrm{B}$ and $\mathrm{N}$ atoms to GO, indicating successful $\mathrm{B}$ and $\mathrm{N}$ doping on the GO. In addition, the higher binding energy of both B1s main peak $(191.7 \mathrm{eV})$ and shoulder peak $(190.4 \mathrm{eV})$ than that of the pure boron $(187 \mathrm{eV})$ indicates the bonding of B with $\mathrm{N}$ and $\mathrm{C}$ atoms [11]. The N1s peak located at 398.3 and $400.4 \mathrm{eV}$ indicates that the $\mathrm{N}$ atoms were incorporated to pyridinic- $\mathrm{N}$ and pyrrolic- $\mathrm{N}$, respectively, also indicating the successful doping of $\mathrm{N}$ 

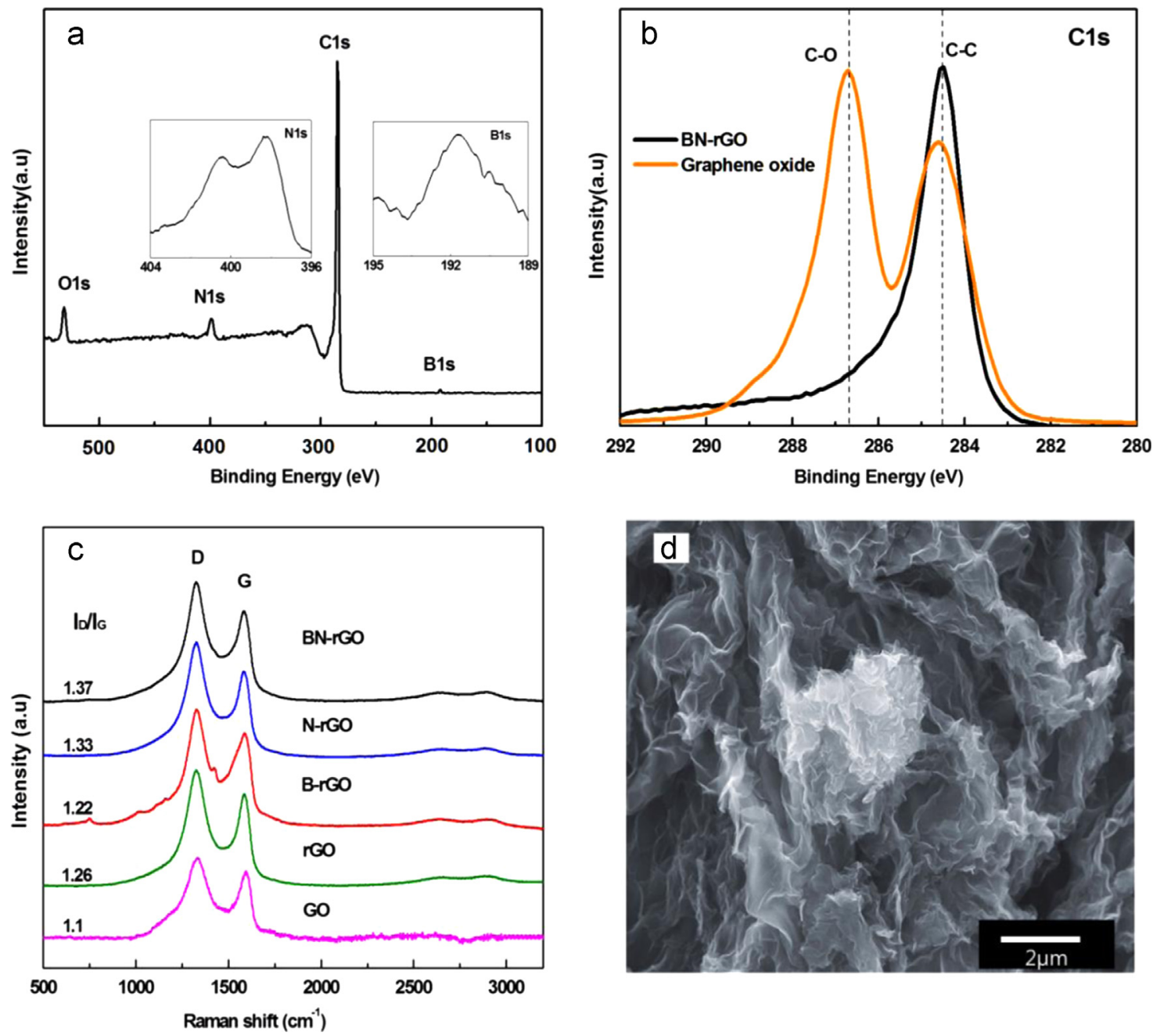

Fig. 1. (a) The XPS survey spectrum of the BN-rGO. Inset: XPS spectra of B1s (right) and N1s (left). (b) C1s XPS spectra of the pristine GO and BN-rGO. (c) Raman spectra of GO, rGO, B-rGO, N-rGO, and BN-rGO. (d) The SEM image of the BN-rGO.

atoms to GO [12]. Fig. 1(b) shows that the main peak position of C1s $(284.4 \mathrm{eV})$ was unchanged after the doping, but the shoulder peaks significantly decreased at a high binding energy, indicating the reduction of the oxygen-related functional groups of GO during the acid treatment and thermal annealing [10]. The elemental analysis shows that the $\mathrm{B}$ and $\mathrm{N}$ contents of $\mathrm{BN}-\mathrm{rGO}$ were highest among all samples and some amount of nitrogen atoms in B-rGO can be incorporated by the NMP (Table 1 ).

The Raman spectra of the GO and doped graphene shown in Fig. 1(c) exhibit two intense peaks at 1328 and $1595 \mathrm{~cm}^{-1}$, corresponding to diamondoid (D) and graphitic (G) peaks, respectively [13]. The higher $I_{\mathrm{D}} / I_{\mathrm{G}}$ value of the BN-rGO than those of B-rGO and N-rGO (Fig. 1c) can be attributed to the formation of B$\mathrm{N}$ bonds on the graphene sheets [12]. The morphology of the BNrGO nanosheet is wrinkled and folded as shown in Fig. 1(d), which enhances the electrochemical reactions due to the formation of mid-gap states [14]. The increased van der Waals force between the rGO sheets after the reduction of the functional groups and the incorporation of heteroatoms such as B and $\mathrm{N}$ caused the wrinkled and disordered structures in the BN-rGO, facilitating the adsorption of oxygen and improving the ORR activity [15].

The cycle voltammogram (CV) of the BN-rGO was studied in the air, $\mathrm{O}_{2}$, and $\mathrm{N}_{2}$ saturated $0.1 \mathrm{M} \mathrm{KOH}$ using a haft-cell system with an $\mathrm{Ag} / \mathrm{AgCl}$ as the reference electrode at a scan rate of $50 \mathrm{mV} \mathrm{s}^{-1}$. As shown Fig. 2(a), an oxygen reduction peak at $-0.37 \mathrm{~V}$ was clearly observed in an $\mathrm{O}_{2}$ saturated environment and decreased in
Table 1

Atomic contents of samples.

\begin{tabular}{lllllr}
\hline & \multicolumn{2}{l}{ Atomic content (\%) } & & \\
\cline { 2 - 6 } & $\mathrm{C}$ & $\mathrm{N}$ & $\mathrm{B}$ & $\mathrm{O}$ & $\mathrm{H}$ \\
\hline B-rGO & 75.9 & 4.7 & 2.2 & 4.2 & 13.0 \\
N-rGO & 85.2 & 6.0 & 0.0 & 2.5 & 6.3 \\
BN-rGO & 80.4 & 6.0 & 3.2 & 2.1 & 8.3 \\
\hline
\end{tabular}

an air-saturated condition and completely disappeared in a $\mathrm{N}_{2}$ saturated condition. The highest peak intensity of the BN-rGO in the $\mathrm{O}_{2}$-saturated environment indicates its electrocatalytic oxygen reduction capability in the alkaline media, and thus potential candidates for metal-free electrocatalysts of AAEMFCs.

Linear sweep voltammetry (LSV) of the BN-rGO was performed using the Rotating disk electrode (RDE) in an $\mathrm{O}_{2}$ saturated $0.1 \mathrm{M}$ $\mathrm{KOH}$ solution at a scan rate of $10 \mathrm{mV} \mathrm{s}^{-1}$. Fig. 2(b) shows that the current density of the BN-rGO was the highest among those of the B-rGO, N-rGO, rGO, and GO, indicating the synergetic effects of B and $\mathrm{N}$ atoms on the ORR activity. To investigate the kinetics during the ORR for each sample, the electron transfer number was obtained and compared by changing rotating speed of the RDE. The electron transfer number for ORR was obtained from the 
a

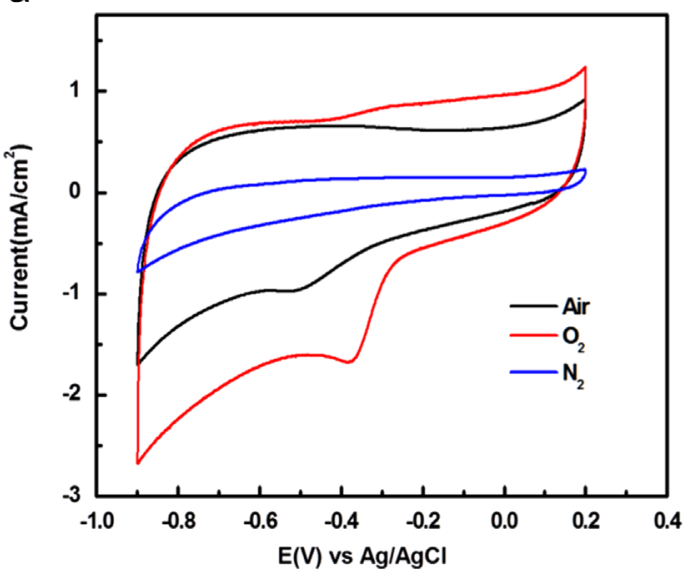

C

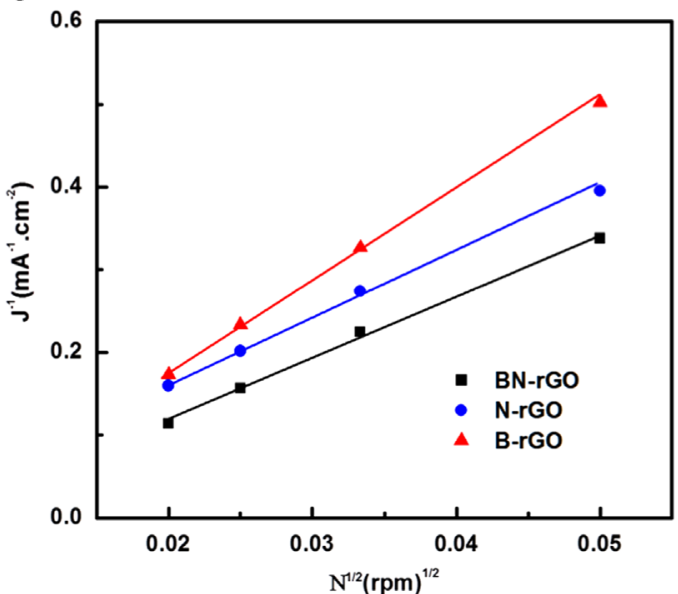

b

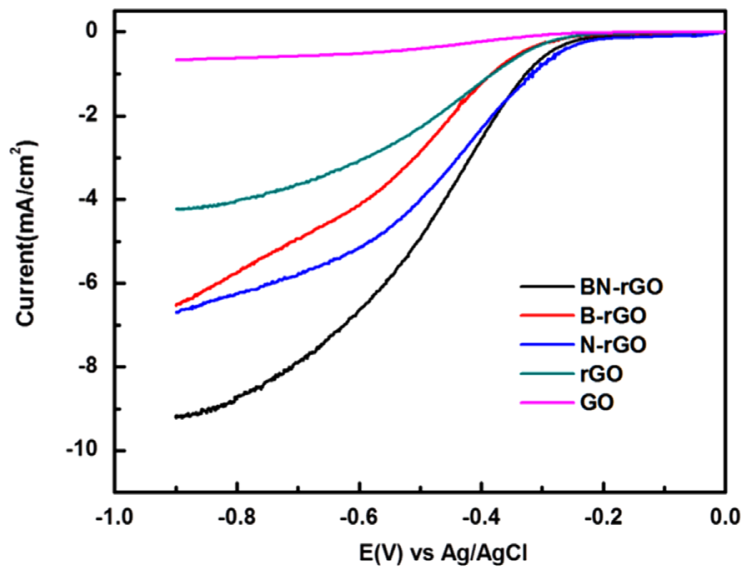

d

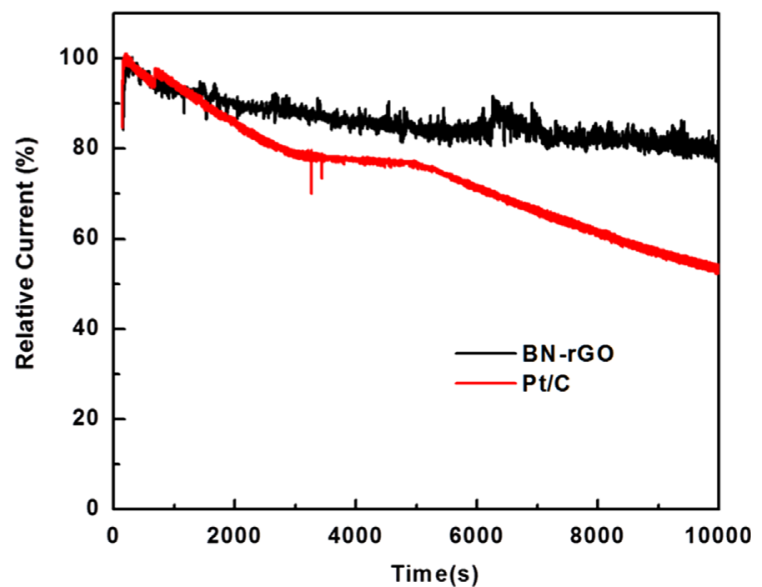

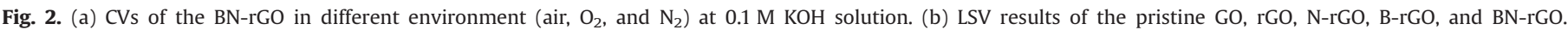

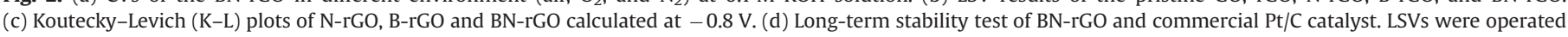
using the $\mathrm{RDE}$ in $\mathrm{O}_{2}$ saturated $0.1 \mathrm{M} \mathrm{KOH}$ solution at $1600 \mathrm{rpm}$ and $-0.4 \mathrm{~V}$.

Koutecky-Levich (K-L) equation

$\frac{1}{J}=\frac{1}{J_{\mathrm{L}}}+\frac{1}{J_{\mathrm{K}}}=\frac{1}{B \omega^{1 / 2}}+\frac{1}{J_{\mathrm{K}}}$

$B=0.62 n F A C_{0}\left(D_{0}\right)^{2 / 3} v^{-1 / 6}$

where $J$ is the measured current $(A), J_{K}$ is the kinetic limiting current $(A), J_{L}$ is the diffusion limiting current $(A), n$ is the electron transfer number per oxygen molecule involved in the ORR, $F$ is the Faraday constant, $A$ is the cross sectional area of the glassy carbon electrode with a diameter of $3 \mathrm{~mm}, D_{0}$ is the diffusion coefficient of $\mathrm{O}_{2}$ in $0.1 \mathrm{M} \mathrm{KOH}, C_{0}$ is the bulk concentration of $\mathrm{O}_{2}$ in $0.1 \mathrm{M} \mathrm{KOH}, \nu$ is the kinematic viscosity of $0.1 \mathrm{M} \mathrm{KOH}$, and $\omega$ is the angular velocity of the disk. The value of $n$ represents the number of electrons transferred per oxygen molecule, and can be calculated from $B$ by using Eqs. (1) and (2) and parameters [16]. As shown in Fig. 2(c), the electron transfer number of the BN-rGO (3.8) was similar to 4, indicating that the oxygen reduction occurs on the $\mathrm{BN}-\mathrm{rGO}$ via efficient four-electron pathways. Moreover, it was higher than those of the N-rGO (3.5) and B-rGO (2.6). These results further indicate the higher ORR activity of the $\mathrm{B}$ and $\mathrm{N}$ codoped $\mathrm{BN}-\mathrm{rGO}$ catalyst than those of single atom doped N-rGO and B-rGO.

The durability of the $\mathrm{BN}-\mathrm{rGO}$ was tested at $-0.4 \mathrm{~V}$ in $\mathrm{O}_{2}$ saturated $0.1 \mathrm{M} \mathrm{KOH}$ solution at a rotation rate of $1600 \mathrm{rpm}$. As shown in Fig. 2(d), after 10,000 seconds of reaction time, the ORR current of BN-rGO was maintained at $\sim 80 \%$, which was higher than that of the commercial Pt/C catalyst $\left(\operatorname{HiSPEC}^{\mathrm{TM}} 4000\right.$, Johnson
Matthey, $53 \mathrm{wt} \% \mathrm{Pt}$ ) under the same condition. Moreover, the deactivation slope of $\mathrm{BN}-\mathrm{rGO}$ is $\sim 12$ times smaller than that of commercial $\mathrm{Pt} / \mathrm{C}$, exhibiting much more enhanced long-term durability of the $\mathrm{BN}-\mathrm{rGO}$ over the $\mathrm{Pt} / \mathrm{C}$ catalyst at a longer operation time. The BN-rGO is believed to avoid the agglomeration of the metal nanoparticles owing to its metal-free nature and the carbon corrosion owing to the strong graphitic structure of rGO, which resulted in enhanced long-term durability.

The CO poisoning causes significant catalyst deactivation in the fuel cells, because of the easy coordination of $\mathrm{CO}$ molecules to the active metal surface [17]. To investigate the CO tolerance, the RDE was performed in the presence of $1.5 \mathrm{M}$ methanol for the BN-rGO and commercial Pt/C catalysts. Fig. 3 shows that the half-wave potential $\left(\mathrm{E}_{1 / 2}\right)$ of the $\mathrm{BN}-\mathrm{rGO}$ was slightly shifted to the negative direction for the ORR $(<10 \mathrm{mV})$, and the current at $-0.4 \mathrm{~V}$ was changed only $0.1 \mathrm{~mA} \mathrm{~cm}^{-2}$. In contrast, the $\mathrm{E}_{1 / 2}$ of $\mathrm{Pt} / \mathrm{C}$ was highly shifted $(250 \mathrm{mV})$, and the current at $-0.4 \mathrm{~V}$ was decreased as high as $5.6 \mathrm{~mA} \mathrm{~cm}^{-2}$, indicating that the BN-rGO is almost immune to the $\mathrm{CO}$ and methanol poisoning.

\section{Conclusions}

The $\mathrm{B}$ and $\mathrm{N}$ codoped graphene oxide was synthesized by a simple one-step solution process using boric acid and nitric acid mixture. The electrochemical analysis showed that the BN-rGO exhibited highly improved ORR activity in the alkaline media than 
a

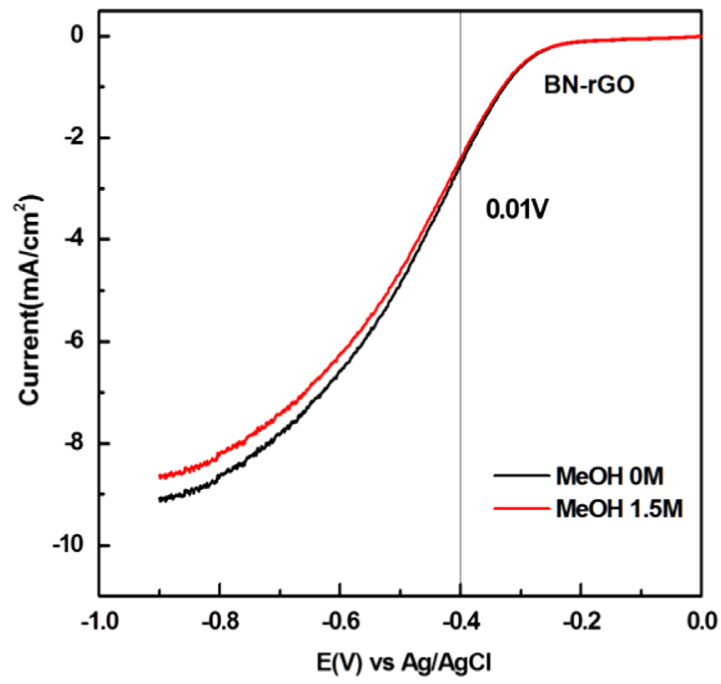

b

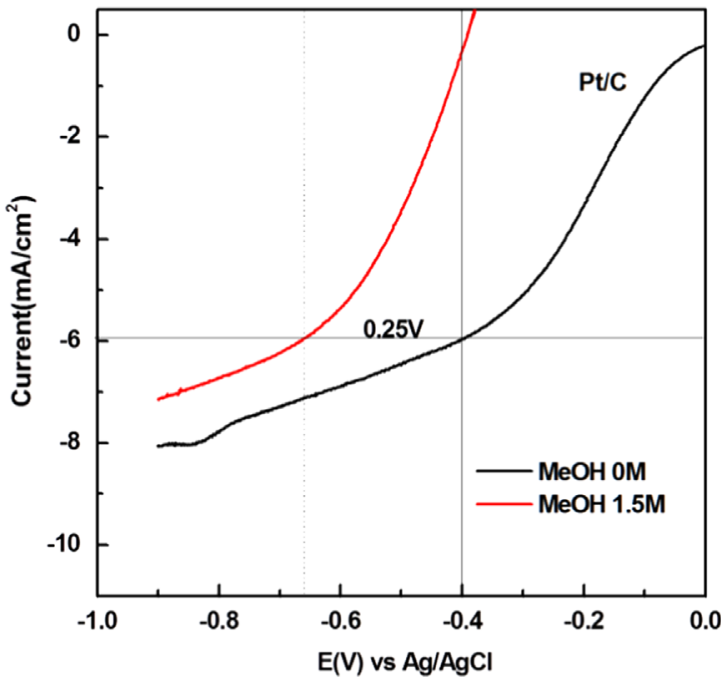

Fig. 3. The LSV results of (a) the BN-rGO and (b) commercial Pt/C catalyst with and without $\mathrm{MeOH}$ in $\mathrm{O}_{2}$ saturated $0.1 \mathrm{M} \mathrm{KOH}$ at a $10 \mathrm{mV} \mathrm{s}^{-1}$ scan rate and $2500 \mathrm{rpm}$.

those of the single doped rGO, rGO, and pristine GO owing to the enhanced oxygen adsorption. Because of the immunity to the metal nanoparticle agglomeration and the CO poisoning, highly improved long-term stability and resistance to the $\mathrm{CO}$ poisoning was observed compared to the commercial Pt/C catalyst.

\section{Acknowledgments}

This research was supported by Basic Science Research Program through the National Research Foundation of Korea (NRF) funded by the Ministry of Education, Republic of Korea (NRF2012K2A1A2030902).

\section{References}

[1] Kong XK, Chen CL, Chen QW. Chem Soc Rev 2014;43:2841-57.

[2] Hibino T, Kobayashi K, Heo P. Electrochim Acta 2013;112:82-9.

[3] Merle G, Wessling M, Nijmeijer K. J Membr Sci 2011;377:1-35.
[4] McLean GF, Niet T, Prince-Richard S, Djilali N. Int J Hydrogen Energy 2002;27:507-26.

[5] Park HY, Shin TJ, Joh HI, Jang JH, Ahn D, Yoo SJ. Electrochem Commun 2014;41:35-8.

[6] Hur SH, Park JN, Asia-Pac J. Chem Eng 2013;8:218-33.

[7] Paraknowitsch JP, Thomas A. Energy Environ Sci 2013;6:2839-55.

[8] Xu J, Dong G, Jin C, Huang M, Guan L. Chem Sus Chem 2013;6:493-9.

[9] Choi CH, Chung MW, Park SH, Woo SI. Phys Chem Chem Phys 2013;15:1802-5.

[10] Tien TN, Luan VH, Lee TK, Kong BS, Chung JS, Kim EJ, et al. Chem Eng J 2012;211-212:97-103.

11] Sheng ZH, Gao HL, Bao WJ, Wang FB, Xia XH. J Mater Chem 2012;22:390-5.

[12] Zheng Y, Jiao Y, Ge L, Jaroniec M, Qiao SZ. Angew Chem Int Ed 2013;52:3110-6.

[13] Lomeda JR, Doyle CD, Kosynkin DV, Hwang WF, Tour JM. J Am Chem Soc 2008;130:16201-6.

[14] Boukhvalov DW, Katsnelson MI. J Phys Chem C 2009;113:14176-8.

[15] Lai L, Potts JR, Zhan D, Wang L, Poh CK, Tang C, et al. Energy Environ Sci 2012;5:7936-42.

[16] Byeon A, Lee JW. J Phys Chem C 2013;117:24167-73.

[17] Ahmed M, Dincer I. Int J Energy Res 2011;35:1213-28. 